\title{
ModOS DE VIDA DA POPULAÇÃO EM SITUAÇÃO DE RUA: INVENTANDO TÁTICAS NAS RUAS DE VITÓRIA/ES \\ http://dx.doi.org/10.1590/1984-0292/1192
}

\author{
Gilderlândia Silva Kunz', Ana Lucia Heckert' ${ }^{\star}$, Silvia Vasconcelos Carvalho IeII \\ ${ }^{I}$ Universidade Federal do Espírito Santo, Vitória, ES, Brasil \\ ${ }^{I I}$ Universidade Federal Fluminense, Niterói, RJ - Brasil
}

\section{RESUMo}

Este artigo visa compartilhar análises acerca dos modos de vida da população de rua. A pesquisa realizada abarcou três momentos: o primeiro visou uma aproximação com moradores de rua para mapear as políticas que atravessam a vida nas ruas; o segundo objetivou o mapeamento dos grupos em situação de rua, destacando as paisagens urbanas com as quais efetua relações sociais; um terceiro momento: em que conversamos de forma mais detalhada com alguns moradores de rua acerca das táticas e astúcias que tecem em seu cotidiano de vida. A pesquisa mostrou que a população de rua reinventa espaços e objetos em seu cotidiano de vida nas ruas, driblando proibições e limites, ressignificando objetos, lugares e usos, bem como produzindo desenhos variados no tecido urbano. A pesquisa também evidenciou as práticas de intolerância e violência contra a população em situação de rua, bem como a violação de seus direitos sociais e políticos.

Palavras-chave: população em situação de rua; políticas públicas; direitos sociais.

\section{The WAYS OF LIFE OF THE HOMELESS:}

\section{INVENTING TACTICS IN THE STREETS OF VITÓRIA / ES}

\section{Abstract}

This article aims to share analysis on the ways of life of the homeless. The research encompassed three stages: the first aimed to get closer from the groups of homeless people to map the policies that cross the life in the streets; the second aimed to map the groups on the streets, highlighting the urban landscapes in which this population makes social relations; a third time we talked in more detail with some homeless people about the tactics and gimmicks that they weave in their daily life. Research has shown that the homeless population reinvents spaces and objects in their daily life on the streets, dodging bans and limits, re-signifying objects, places and uses, as well as producing various designs in the urban tissue. The survey also highlighted the practices of intolerance and violence against the homeless population, as well as the violation of their social and political rights.

Keywords: homeless population; public policies; human rights.

\footnotetext{
^Endereço para correspondência: Universidade Federal do Espírito Santo, Departamento de Psicologia. Avenida Fernando Ferrari s/nº - Goiabeiras. 29060-900 - Vitoria, ES - Brasil.

E-mail: gilkunz@hotmail.com, anaheckert@uol.com.br, silviacj@superig.com.br
} 


\section{INTRODUÇão}

As publicações que têm como objeto a população de rua no Brasil são, em grande parte, voltadas para a análise de fatores políticos, sociais e econômicos relacionados a essa população. Como salienta Mendes (2007, p. 3) em estudo realizado acerca da população de rua em Belo Horizonte (MG):

Assim sendo, a maioria dos autores que escrevem sobre a população de rua enfatiza questões como o desemprego, os reflexos da crise mundial, as mudanças estruturais da economia, a crise social provocada pelo crime organizado e o tráfico de drogas e a ideologia neo-liberal, entre outros [...].

Para além das questões de ordem econômica, outros autores como Silva (2009) assinalam que a ocupação das ruas se efetua também em função da fragilização dos vínculos familiares. Outra vertente de trabalhos relacionadas a esse tema, e em número mais restrito, como os de Kasper (2006) e Lima (1998), destacam pesquisas com esses grupos que se esforçam no sentido de mergulhar nesta experiência, convivendo com suas rotinas e práticas diárias - seus modos de vida - e com eles tecer saberes da/na rua.

Essas pessoas e grupos que vivem nas ruas das cidades, os supérfluos (CASTEL, 1998), têm sido alvo de um campo de indagações e intervenções, bem como do uso de velhas e novas estratégias de controle de suas vidas. A inexistência de dados acerca da população de rua até o início do século XXI coloca em análise o lugar destes sujeitos na polis contemporânea e a relação que o Estado tem estabelecido, historicamente, com esses sujeitos considerados como "sem eira nem beira". Não sendo possível apagar estas existências da vida na cidade, recentemente vimos ações do poder público no sentido de mapear a população de rua em nosso país.

Uma pesquisa nacional sobre a população em situação de rua, encomendada pelo Ministério do Desenvolvimento Social e Combate à Fome/MDS (BRASIL, 2009a) e realizada em 71 municípios brasileiros no período de 2007 a 2008, mostrou que o Brasil tem 31.922 mil moradores de rua. Contudo a estimativa do Movimento Nacional da População em Situação de Rua (MNPR) é de que esse número seja de 50 mil pessoas. Importa ressaltar que este foi o primeiro censo realizado acerca da população em situação de rua no Brasil.

Este estudo também revelou que a população de rua é majoritariamente masculina, 53\% encontra-se na faixa etária entre 25 e 44 anos e 39,1 \% declaramse como pardos e $27,9 \%$ negros. A pesquisa apontou também a existência de 700 pessoas em situação de rua na Região Metropolitana da Grande Vitória. Outro aspecto indicado é: a população em situação de rua não é um grupo homogêneo mas heterogêneo, em sua maioria afrodescendente, nele se encontrando flanelinhas, catadores de materiais recicláveis, malabares, egressos do sistema prisional, pessoas com sofrimento psíquico e pedintes. Uma característica de quase todos os grupos é a baixa escolarização, o desemprego e a ausência de domicílio fixo. Muitos migram também de grandes metrópoles, tais como Salvador (BA) e 
Belo Horizonte (MG) e sinalizam que, em algumas cidades, o único serviço de acolhimento voltado à população em situação de rua são as passagens ofertadas pelo poder público municipal para que se dirijam a outras cidades ou estados. Há quem colecione bilhetes de viagem.

No estado do Espírito Santo somente a prefeitura de Vitória mantém uma restrita rede de atenção à população moradora de rua que, mesmo sendo considerada modelo para os demais municípios, convive com imensas fragilidades: os albergues estão lotados, a infraestrutura é precária, o mobiliário é sucateado, existem poucos leitos, os funcionários estão insatisfeitos pois são mal remunerados. Estressados e com sobrecarga de trabalho, alguns chegam a adoecer. Faltam qualificação e capacitação adequadas para lidar com esse público morador de rua e, principalmente, falta vontade política dos governos municipal e estadual para investir nessa área. A gestão desses espaços é compartilhada com ONG's e os recursos são repassados pela municipalidade por meio de convênios ou contratos. A manutenção dos espaços de albergamento gera um alto custo para a municipalidade e é pouco eficaz com relação às demandas da população de rua.

Com o advento da Constituição Federal de 1988, que considerou os direitos sociais como direitos fundamentais de todo cidadão, e com a Lei Orgânica da Assistência (LOAS), que regulamenta os artigos da Constituição Federal e reconhece a Assistência Social como Política Pública e de responsabilidade do Estado (BRASIL, 2005), e mais recentemente, em dezembro de 2009, com a Lei Federal que instituiu a Política Nacional para a População em Situação de Rua (BRASIL, 2009b), inúmeros direitos foram garantidos em leis, inclusive apontando que a população de rua deveria ser incluída como prioridade nas ações de governo. Todavia, pode-se dizer em linhas gerais que nos últimos anos poucas iniciativas públicas destinadas a essa população se concretizaram.

A par disso, o esvaziamento dos espaços públicos e a acelerada privatização dos espaços da cidade têm igualmente contribuído para incrementar processos de segregação e isolamento social. A cidade é esquadrinhada de forma a impedir/reduzir as misturas e a circulação, opondo casa e rua, público e privado, centro e periferia. Os mais pobres, que escapam às políticas de segregação espacial da miséria são constantemente empurrados para espaços de moradia nas periferias urbanas, mas ocupam as ruas da cidade e se constituem como uma "ameaça à segurança', à 'ordem da polis".

Da mesma forma, a construção de verdadeiras barricadas nas cidades, por meio da instalação de grades e cercas em praças e edifícios, emerge como procedimento de proteção ao cidadão comum. Portanto, conforme aponta Gomes (2006, p. 67), "[...] pensar a questão da população em situação de rua envolve pensar a cidade como um todo e as relações sociais aí produzidas". Envolve discutir as relações de poder-saber que constituem esta parcela da população em alvo de políticas governamentais que acabam por lançar mão de procedimentos que visam conter a mobilidade destes sujeitos nos espaços da cidade, e garantir 
a ordem sob o manto da defesa dos direitos de segurança de alguns. Implica a análise de dispositivos de poder que tem como efeito a criminalização dos modos de vida que destoam daqueles já instituídos.

\section{DE “COCORINHA” NAS RUAS}

Nesse artigo apresentamos parte dos resultados da pesquisa "Modos de vida da população de rua: narrativas de andanças nas ruas de Vitória" que se propôs a estudar os modos de vida da população em situação de rua. Objetivou-se dar visibilidade às diversas táticas que movimentam com vigor esses modos de vida e que é cotidianamente invisibilizada. Invisibilidade que consideramos como expressão de práticas de silenciamento e desqualificação dos modos de vida desse grupo social.

A pesquisa procurou acompanhar os processos que se desenrolam na vida da população em situação de rua, seus modos de viver que evidenciam novas formas de fazer, existir e ocupar a cidade, traçando redes de comunicação e contando histórias de sofrimentos, indignação, apostas e ilusões. Para isso, tomou-se o cuidado de não naturalizar os lugares prontos do morador de rua, da miséria e da pobreza, bem como não moralizar ou romantizar os processos de sucateamento da vida com que convivem, mas desviar o olhar para manhas, astúcias e táticas de vida e sobrevivência criadas por essas pessoas na condição de moradores de rua, e percorrer os traçados que efetuam na cidade, ouvindo suas histórias, tateando seus modos de viver.

Modos de vida são entendidos nesta pesquisa como maneiras de viver tecidas em meio aos exercícios éticos e aos valores morais e são fabricados nas relações sociais. São processos de construção sempre coletiva. Como sugere Fuganti (2001, p. 2),

[...] é no modo de vida que está o segredo de qualquer coisa. A pedra de toque da liberdade, da escravidão, do pensamento, da submissão à sabedoria, está sempre no modo de vida. O modo de viver é simultaneamente ético e estético. Ele cria regras éticas, que podem até ser regras morais, e ao mesmo tempo ele expressa um modo da energia ou do desejo atravessar o corpo que faz do corpo e da alma uma expressão estética, uma obra de arte. Ou um trapo.

Iniciamos nossa construção nesse caminhar a partir das pistas do método cartográfico, seguindo os dizeres de Passos e Barros (2009, p. 17), ao afirmarem que conhecer, fazer pesquisa e intervir são ações inseparáveis, pois "[...] toda pesquisa é intervenção". Os autores acentuam ainda que “[...] a intervenção sempre se realiza por um mergulho na experiência que agencia sujeito e objeto, teoria e prática, num mesmo plano de produção ou de coemergência [...]" (PASSOS; BARROS, 2009, p. 17). Para eles, a cartografia visa acompanhar os efeitos que a pesquisa efetua sobre o 'objeto', o pesquisador e os saberes daí decorrentes. $\mathrm{Na}$ 
rua, com a população moradora de rua, nos colocamos na posição da "cocorinha" que, segundo Alvarez e Passos (2009, p. 144), "[...] pode servir de exemplo da habitação de um território de pesquisa pelo aprendiz-cartográfico".

Traçar cartografias diz respeito a apontar as micropolíticas que tecem os mais diversos modos de inserção social, buscando a constituição de outros territórios, outros espaços de vida e de afeto, para aqueles que se encontram paralisados, que se apresentam sem saída (GUATTARI; ROLNIK, 1986, p. 14). Esse processo é o que caracteriza a pesquisa cartográfica e se propõe a acompanhar a construção de territórios existenciais, seguindo os processos de produção e experimentação de modos de vida e abolindo a separação entre pesquisador e campo pesquisado, entre a clássica divisão sujeito e objeto. Cabe destacar, ainda, o caráter construtivista da atividade cartográfica e a dimensão coletiva desta construção. A cartografia tem sido utilizada no campo das ciências humanas como método analítico-processual, ou seja, de acompanhamento da dinâmica dos processos que se interessa pelos movimentos e mutações que os viventes efetuam ao traçarem territórios existenciais (DELEUZE; GUATTARI, 1995).

\section{Praticantes da Cidade inventando Percursos e movimentos}

As noções de táticas, astúcias e estratégias, propostas por Certeau, nos pareceram apropriadas para realçar as produções tecidas no cotidiano da população de rua. Tais criações nos indicam que "[...] mesmo os estados de dominação são porosos, permitem a invenção de novas possibilidades de vida e criação, cujo maior desafio é sua própria sustentação e multiplicação como formas de subjetivação." (CERQUEIRA, 2010, p. 28). Consideramos a população de rua como aqueles que Certeau (2008, p. 171) denomina de "praticantes ordinários da cidade": os caminhantes e pedestres que diariamente andam e se movimentam cruzando a cidade. $\mathrm{O}$ autor aponta que essa experiência urbana elementar de caminhar produz interferências e reinventa as finalidades claras e distintas dos lugares urbanos previamente definidos, dando a estes outros usos e sentidos, o que possibilita a experimentação de outras práticas urbanas que se insinuam "[...] no texto claro da cidade planejada" (CERTEAU, 2008, p. 172) e fazem com que a cidade permaneça "[...] cotidianamente, indefinitivamente, outra" (CERTEAU, 2008, p. 171).

Tais interferências se realizam por meio de operações temporais que se apropriam dos lugares com seus usos definidos e apropriados, transformando-os em espaços de múltiplos usos. É o que ocorre quando as ruas, lugares de passagem como disse também um de nossos entrevistados, tornam-se espaço de encontro para movimentos que impedem exatamente a locomoção dos transeuntes, estes sempre acompanhados de perto pelo aparato policial, a postos para cuidar dos lugares próprios do patrimônio público. Quando as ruas de alguns bairros se transformam em espaço de jogo - campo de futebol -, ou quando as ruas, ainda elas, viram espaço de moradia para aqueles que não têm casa. 
Certeau (2008, p. 100) dá o nome de táticas a essas práticas de apropriação que são "[...] determinadas pela ausência de um próprio, [...] não tem por lugar senão o do outro". A tática é efetuada por alguém a partir de um lugar que não é seu, é de outro.

Aproveita "as ocasiões" e delas depende, sem base para estocar benefícios, aumentar a propriedade e prever saídas. O que ela ganha não se conserva. Este não lugar lhe permite sem dúvida mobilidade, mas numa docilidade aos azares do tempo, para captar no vôo as possibilidades oferecidas por um instante. Tem que utilizar, vigilante, as falhas que as conjunturas particulares vão abrindo na vigilância do poder proprietário. Aí vai caçar. Cria ali surpresas. Consegue estar onde ninguém espera (CERTEAU, 2008, p.101) .

Ela é astúcia, companheira dos azares do tempo. É “[...] a arte de dar golpes", diz Certeau (2008, p. 101), ou, como falamos em nosso país, de "dar nó em pingo d'água", desestabilizando os traçados existentes.

A estratégia, por outro lado, se efetua, segundo Certeau (2008), quando um lugar próprio é circunscrito. Para o autor ela é: “[...] o cálculo (ou a manipulação), das relações de forças que se torna possível a partir do momento em que um sujeito de querer e poder (uma empresa, um exército, uma cidade, uma instituição cientifica) pode ser isolado" (CERTEAU, 2008, p. 93).

Oposta à tática, a estratégia requer a existência de lugares próprios como condição para o seu exercício, que são os lugares formais e reconhecidos na organização geral da cidade, quer eles sejam as instituições que detêm formalmente o poder de controlar e vigiar a cidade e a população, como a polícia, o exército, ou outras instituições cujo poder seja mais restrito ao lugar onde se estabelece, como escolas, estabelecimentos comerciais, moradias, habitações, condomínios ou mesmo os lugares públicos, regidos por normas e regulamentos de convívio social e por códigos de posturas.

De modo a sobreviver na cidade, os moradores de rua criam táticas e usam de astúcias para driblar proibições e limites, ressignificando objetos, lugares e usos, bem como produzindo desenhos variados no tecido urbano. Em nossa busca para entrevistar os moradores de rua, pautada por atrasos, desencontros e longas esperas para encontrá-los, mais uma vez nos demos conta da existência dessas outras formas de viver que são tecidas dentro da cidade.

Para os moradores de rua, deslocar-se faz parte dos modos de viver e sobreviver. Seus trajetos não seguem rotas definidas por critérios geográficos para chegar a lugares específicos, mas se orientam considerando as redes de suporte já conhecidas ou as que podem vir a ser promissoras e, sobretudo, evitando os lugares em que ações repressivas podem estar acontecendo ou que aconteceram recentemente. Assim, observamos que mesmo os espaços mais familiares para eles se encontram marcados pelo signo da provisoriedade. 
Os caminhos e lugares de parada que escolhem para dormir, morar, comer, divertir-se, fazer seus "bicos" que lhes rendem algum dinheiro e os usos que fazem dos equipamentos urbanos, são definidos por percursos e não por mapas. Estes (os mapas), segundo Certeau (2008), são elaborados a partir do conhecimento de lugares e da ordem com que são arrumados na cidade. Com um mapa é possível traçar um itinerário, pois cada lugar ocupa uma posição própria e estável, tem endereço fixo. O percurso, ao contrário, é orientado pelos espaços que, dito anteriormente, são o efeito das apropriações e experiências efetivadas e praticadas pelos moradores da cidade que introduzem tempo e movimento na fixidez do lugar. Por isso, para chegar em tal ou qual espaço efetuam-se movimentos e organizam-se operações : ir em frente, atravessar uma ponte, subir um viaduto, contornar uma casa, dar um outro nome à rua, etc.

Mais uma vez tomamos de empréstimo as análises de Kasper (2006) que discute as diversas formas e ritmos que o povo da rua emprega ao usar os logradouros públicos, contrariando ou ignorando, conforme o autor afirma, os usos previstos: morar embaixo de marquises, nas calçadas, praças e bancos; ocupar terrenos baldios e imóveis abandonados, sejam eles públicos ou privados. Este autor nos ajuda a perceber que a população em situação de rua reinventa outros usos para os equipamentos e objetos e que são diversos daqueles para os quais foram inicialmente criados. Por exemplo, transformam sucatas em utensílios domésticos ou "instrumentos de defesa".

Não restam dúvidas de que, nos modos de vida da população urbana, aí incluída a população em situação de rua, existe "[...] uma criatividade que se esconde num emaranhado de astúcias silenciosas e sutis, eficazes, pelas quais cada um inventa para si mesmo uma "maneira" de caminhar pela floresta dos produtos impostos” (CERTEAU, 2011, p. 13).

\section{As ruas da Cidade: UM lugar de apostas e de MAU TRATo}

A pesquisa que desenvolvemos com a população de rua abarcou três momentos: o primeiro, que designamos como um estudo exploratório, realizada na região central da cidade de Vitória/ES, visou uma aproximação com os grupos de moradores de rua para mapear as políticas que atravessam a vida nas ruas; o segundo, que objetivou o mapeamento dos grupos em situação de rua na cidade de Vitória, destacando as paisagens urbanas nas quais esta população efetua relações sociais e as astúcias criadas na vida cotidiana; um terceiro momento em que, a partir do mapeamento efetuado, foram definidos alguns moradores de rua com os quais conversamos de forma mais detalhada acerca das táticas e astúcias que tecem em seu cotidiano de vida.

Com base nessas considerações e caminhando com os moradores de rua em seus percursos, buscamos apresentar as maneiras de fazer a vida na rua, os usos e manejos de táticas e astúcias que inventam para sobreviver na cidade, compondo o que denominamos neste trabalho como modos de vida. 
Recortamos, assim, algumas táticas e astúcias por nós percebidas nesta pesquisa, tais como: alimentação, correria, regras, relação com a cidade, incluindo aqui as igrejas, comerciantes, segurança pública, banho, cuidado com os pertences pessoais, o trabalho que realizam na rua, dentre outros, que de algum modo expressam como se desenrola a vida nas ruas. Como aponta Gomes (2006, p. 17), habitar as ruas "[...] implica em deixar-se permear pela diversidade da vida nas grandes cidades."

Em relação ao primeiro momento da pesquisa, foi possível perceber que os moradores de rua conhecem bem a rede de apoio do poder público, pois às vezes pedem ajuda pelo telefone 156, acionando diretamente o Serviço de Abordagem de Rua, ${ }^{1}$ mas raramente buscam os serviços públicos de saúde. São vários obstáculos que esta população tem de enfrentar para acessar esses serviços de saúde - desde as práticas de preconceito, bem como o temor de terem suas existências controladas. Contudo, lançam mão de saberes ditos "populares" e de redes de solidariedade para enfrentarem os agravos cotidianos à saúde. As mulheres mais velhas recorrem aos chás com folhas medicinais e, em casos graves, também solicitam apoio de comerciantes ou de moradores conhecidos. É necessário salientar que há moradores de rua que estabelecem relações de proximidade com os demais moradores da cidade, e é com estas redes que também vão tecendo os cuidados com a vida.

Os moradores de rua com os quais conversamos, frequentemente queixamse dos espaços de albergamento, dizem que nos abrigos são tratados como crianças: "Tudo tem que ter hora", "Não tem um cantinho só prá mim, é uma bagunça todo mundo junto". Não é permitido casais dormirem juntos nos abrigos. Segundo a população em situação de rua há ainda um excesso de regras com as quais não conseguem lidar. Como os abrigos funcionam como espaços de disciplinarização e controle, com regras e valores que se confrontam àqueles tecidos nas ruas, estes espaços são apropriados de forma restrita pelos moradores de rua.

Cabe ressaltar que a vida na rua não se efetua sem a constituição de uma política informal de moradia praticada por aqueles que têm na rua seu próprio lugar de moradia. Habitar a rua requer astúcia, fabricação e compartilhamento de saberes, prontidão dos sentidos, como apontou Milton Santos (2000) acerca dos despossuídos. Implica lidar com a imprevisibilidade permanentemente.

O povo morador das ruas se apropria de terrenos baldios, casas, prédios abandonados, de espaços embaixo de pontes, praças e marquises. Ao descobrirem imóveis ou terrenos baldios, que estão desocupados, ociosos ou abandonados, apossar-se deles não é entendido por estes grupos como invasão, e sim ocupação. Para saber se existem imóveis abandonados na cidade, os moradores de rua precisam mapeá-los constantemente. Eles bem sabem que não ficarão por muito tempo no mesmo lugar, em função da pressão cotidiana das políticas públicas e dos demais moradores da cidade que os obrigam a circular pelos espaços da cidade.

Quando o morador de rua se movimenta, ele sabe para onde vai, pois já conhece os imóveis abandonados na cidade que vai ocupar. Ele vive e circula por uma área por eles circunscrita, demonstrando, assim, que a rua não é um espaço 
indiferente para ele. Um conjunto de fatores define esta ocupação dos espaços, que se faz em função da "permissão social" para ocupação ou da ocorrência de menor pressão do poder público e dos demais moradores da cidade. Porém, será sempre um lugar estratégico que será ocupado, ou seja, aquele que de algum modo favorece a sua sobrevivência.

A vida na rua não dispensa regras e cuidados. Dormem nas ruas, mas dormem atentos e preferem dormir quando o dia está amanhecendo, pois é sempre mais seguro. Como indica Baptista: "O tempo dos que são marcados em lugar nenhum é intenso e nervoso [...] ligando-se uns aos outros, o despertar de um, na espreita de algum visitante noturno, desperta todos (BAPTISTA, 1999, p. 97). Assim como aprendem a driblar os sistemas de segurança dos locais usados por eles como abrigo. Sua sobrevivência se efetua realizando pequenos serviços e atendendo aos interesses de muitos comerciantes.

$\mathrm{O}$ viver na rua não se garante com práticas de isolamento e sem trocas, fazse necessário tecer redes de solidariedade. Quem cai na rua não tem como viver sozinho. Para ser aceito "não pode ser um parasita", e isso inclui compartilhar desde o pedir dinheiro ou alimento aos transeuntes, realizar pequenos serviços como limpar a rua, cuidar do lixo de algum estabelecimento comercial, fazer pequenos favores aos comerciantes ou camelôs, dentre outros.

\section{Andando nas RUAS PElo TRAÇAdO da POPUlaÇÃo EM SITUAÇÃo DE RUA}

O segundo momento da pesquisa objetivou cartografar os espaços ocupados pela população em situação de rua e implicou ter a atenção voltada não apenas aos espaços geográficos que habitavam, mas a tudo o que tomava parte nesta paisagem. O objetivo não era o de traçar o desenho de um mapa geográfico da ocupação das ruas da cidade pelos moradores em situação de rua, mas localizar esses espaços pelos quais transitavam a fim de compreender os processos que se passam nas ruas e que, muitas vezes, provocam deslocamentos desta população no espaço urbano. O que visávamos era mergulhar no campo de pesquisa, permanecendo atentos às astúcias criadas para viver nas ruas. Neste percurso, nosso roteiro indicava uma atenção cuidadosa às seguintes questões: o modo como se organizam (individualmente ou em grupos) e habitam as ruas, em que região da cidade estão vivendo, como ocupam os espaços escolhidos, como os grupos são constituídos (adultos, jovens, idosos, etc), qual a sua etnia, como organizam e cuidam de seus pertences pessoais, como se alimentam, como convivem com os demais moradores da cidade, dentre outras questões. Assim, em meio ao asfalto, íamos registrando no diário de campo algumas descrições e impressões deste percurso.

Nossas andanças compreenderam o Centro da Cidade de Vitória, especialmente a Praça Costa Pereira e o Sambão do Povo, a Praça do EPA (Praça Regina Frigeri Furno) em Jardim da Penha e a Praça dos Eucaliptos em Maruípe. Estes locais foram definidos em função da presença da população em situação de rua, da diversidade e singularidade dos modos de vida e das relações que travam 
com os demais moradores da cidade. Sua itinerância nos obrigou a esperar e também a perambular e caminhar pela cidade seguindo pelas mesmas trilhas que eles percorrem, igualmente diversas dos caminhos que utilizamos habitualmente.

Na Praça Costa Pereira se forja uma rede para garantia da alimentação, seja por meio de doações, vindas dos restaurantes e efetuadas de forma extremamente sutil, passando despercebida pelo transeunte que desconhece a vida na praça, seja por meio de doações de igrejas ou ofertadas pelos equipamentos públicos, como o CREAS/Pop. ${ }^{2}$

$\mathrm{Na}$ paisagem da praça e em outros espaços da cidade, territórios também são delimitados, definindo quem exerce o comando e quem pode ser usuário do espaço e usando estratégias de segurança para expulsar os invasores. Há regras claras de convivência que não estão escritas e que nos foram narradas. Há também regras de ocupação dos espaços. Nesta primeira andança pela praça percebemos que a ocupação de prédios, marquises e calçadas relacionam-se à presença do comércio, à possibilidade de garantirem segurança uns aos outros, à existência de casas e prédios ociosos, dentre outros fatores.

A praça é, ao mesmo tempo, ponto de encontro e ponto de passagem. Nas andanças na Praça Costa Pereira, foi possível perceber que ali são forjadas práticas de solidariedade e de troca com os demais moradores da cidade e entre eles, como também nos foram relatadas práticas de violência, seja por parte do aparato policial, seja por parte de cidadãos (moradores domiciliados do entorno, comerciantes, etc) que não toleram a presença dos moradores de rua na Praça. Um homem foi apontado como "aquele sujeito [...] que toca fogo nos colchões dos moradores de rua" (popular de rua).

Em outra praça da cidade encontramos uma moradora de rua, que reside naquele local há aproximadamente 20 anos, dormindo em um dos bancos desta praça. A 'dama limpinha' não sofre ações de repúdio por parte dos moradores da localidade, certamente manter-se 'limpinha' é uma das astúcias criadas para permanecer neste local. O fato é que ali ninguém aciona o serviço Disque 156, da Prefeitura de Vitória para se queixar dessa moradora que é acolhida pela comunidade local.

\section{A ARTE DA CORRERIA}

A correria consiste em várias táticas de sobrevivência que garantem, por meio de ações astuciosas, o dia a dia nas ruas e dentre elas está o "manguear", 3 como costumam dizer. Existem ainda outras práticas muito utilizadas, tais como a realização de pequenos serviços para os cidadãos domiciliados, ${ }^{4}$ comerciantes, barraqueiros das feiras livres, que vendem artesanato ou alimentos, guardar ou vigiar os carros, coletar e vender materiais recicláveis (uma das principais formas de subsistência do povo da rua), por fim, fazer "programas" também pode ser uma alternativa para alguns. 
Há ainda quem se vale de práticas ilícitas, estas ocorrendo em menor frequência. Para tanto aproveitam oportunidades e/ou situações favoráveis. Não quer dizer, no entanto, que aquele que subtraiu um objeto alheio fique impune. Na maioria das vezes é comum encontrarmos em situação de rua pessoas recém-saídas do sistema prisional cujo delito cometido enquadra-se no artigo 155 do código penal. ${ }^{5}$

Manguear "é entrar nas mente da pessoa", nos disse Elisa. Essa prática cotidiana consiste no poder de persuasão por meio de suas narrativas, capaz de sensibilizar o outro e coletar dinheiro entre os transeuntes e comerciantes nas ruas. Contam uma história que possa comover quem ouve, se é ou não verídica, pouco importa. O povo da rua considera que "é melhor pedir do que roubar", entendem ser essa uma artimanha lícita de sobrevivência. Contudo, enganamse os que imaginam que a população moradora de rua sobrevive basicamente da "mendicância". Cabe apontar, segundo a pesquisa realizada pelo MDS (BRASIL, 2009a), que a maioria das pessoas em situação de rua é composta por trabalhadores informais, apenas uma pequena parcela das pessoas em situação de rua pede dinheiro como principal meio para sobrevivência. Essas informações são importantes, pois desmitificam a visão equivocada de que a população em situação de rua é composta por "mendigos" e "pedintes".

\section{A AlimentaÇÃo: as REDES CRIAdAS}

A população de rua não tem hora certa para se alimentar. O que irá determinar o horário da alimentação dependerá de uma combinação de fatores e, como diz Certeau (2008), da ocasião. Boa parte dos moradores de rua conhece os pontos que fornecem alimentos e os horários em que esta ação vai ocorrer. Tais pontos são chamados por eles de "boca de rango". O fogareiro improvisado do "cafofo" fica no "aguardo" para ser utilizado, especialmente nos finais de semana.

Nas conversas realizadas em nossas andanças contaram que são doados por um misterioso funcionário de um dos restaurantes em média cinco quilos por dia de alimentos. Descrevem que, normalmente, os restaurantes depositam o lixo em um recipiente grande para serem recolhidos pelos carros coletores da limpeza pública, e observaram que em um restaurante especifico o lixo é acondicionado de maneira diferente. Quando lhes foi perguntado o que os faz ter a certeza de que esse saco diferenciado seria endereçado a eles, responderam: "[...] porque dentro dele só tem comida boa, a comida é o bastante para todos aqui se alimentar, às vezes sobra."

Outros pontos de alimentação também se estabelecem nessa relação com a cidade. O pessoal da Praça Costa Pereira fez referência às igrejas que durante a noite fornecem alimentação (sopa, pão, frutas, etc.); "[...] é tanta comida que sobra", informaram os moradores que viviam na marquise de um prédio público. Contudo, "antes de servirem alimentação, em círculos e de mãos dadas fazemos uma oração". Essa distribuição é frequentemente realizada nos horários noturnos. Muitos moradores de rua se queixam por serem despertados de súbito enquanto dormem. "Ninguém é acordado para comer de madrugada quando está dormindo em sua casa, por que nós temos que ser acordados na madrugada para tomar sopa?" (moradora de rua). 
O próprio CREAS/ Pop Rua é outro espaço de referência para alimentação e também higienização. A população em situação de rua também frequenta o Restaurante Popular gerido pela administração pública municipal, que funciona de segunda a sexta-feira, no horário de $10 \mathrm{~h}$ as 14 horas, somente para almoço. A refeição no restaurante popular de Vitória custa ao usuário $\mathrm{R} \$ 1,00$. O município de Vitória, em parceria com governo de Estado, arca com o restante do custo. É preciso ressaltar que no restaurante popular de Vitória não há qualquer refeição gratuita e a população em situação de rua precisa "manguear" ou fazer outras correrias para custear sua refeição nesse equipamento público. Sem contar com políticas públicas de alimentação, muitas são as táticas colocadas em ação. $\mathrm{Na}$ maioria das vezes é possível contar com a solidariedade alheia, quando recebem refeições ou mesmo dinheiro, principalmente daqueles moradores da cidade com os quais estabelecem vínculos.

\section{COZINHAR NAS RUAS: INVENTANDO OBJETOS E RECEITAS}

Cozinhar nas ruas é uma alternativa muito utilizada para garantir as refeições, e também um verdadeiro desafio, uma vez que os cidadãos domiciliados sentem-se muito incomodados com essa prática nos logradouros públicos. Os produtos para o cozimento são "mangueados" em supermercados, açougues, peixarias, padarias e feiras livres. Em geral, o modo de cozinhar alimentos nas ruas é muito semelhante em todos os grupos que mapeamos.

"Vamos queimar lata" é o termo utilizado por moradores de rua quando acendem o fogareiro para o cozimento de alimentos. Os utensílios que são usados para serem transformados em um fogareiro são um latão, do qual se tira a tampa, e uma grelha que é colocada em cima deste recipiente e que pode ser retirada de diversos objetos. Neste latão coloca-se álcool comprado em posto de gasolina. O fogo pode também ser alimentado por lenha ou carvão. Latas menores de conservas são utilizadas como panelas. Outros objetos encontrados nas ruas podem facilmente servir para serem transformados em "fogão a lenha". Restos de construções, como tijolos e paralelepípedos, são ajustados de forma que possam acomodar uma grelha. Por vezes um muro qualquer também compõe a fabricação do "fogão a lenha", pois o muro ajuda a proteger o fogo do vento.

Vimos também que os moradores de rua inventam receitas com os diversos alimentos mangueados. Restos e sobras de comida podem ser transformados em refeições e, segundo eles, fica muito saboroso. A pelanca frita (pedaços de carnes com gordura de carne de boi e/ou de frango) tanto pode incrementar o feijão como uma farofa. Outras receitas são reinventadas nas ruas como a canja de pé de galinha feita por Elisa, o café ralo que a "dama limpinha" nos ensinou, como também o miojo no bafo, receita fornecida por Elisa. A hora da alimentação na rua também pode se constituir num momento de festa, seja para comemorar um casamento, um aniversário ou apenas comemorar o encontro entre os iguais. Elisa relata o "banquete" preparado na rua para comemorar sua união com outro morador de rua,

[...] fizemo até um casamento de mentirinha [...] ele colocou um anel no meu dedo, todo mundo batendo palmas, fizemo 
feijoada, suco, salada de fruta. A Cintia fez a cerimônia, [...] tinha bastante cachaça, eu que fiz a feijoada pra 20 pessoas com bastante carne. Esse dia não vou esquecer nunca (Elisa).

Nos momentos em que as doações de alimentos são raras, ou mesmo não acontecem, não resta alternativa a não ser "comer do lixo". Sobreviver do lixo é para muitos uma solução. Não há muito que selecionar, no lixo não há opção de não comer por ser de procedência duvidosa, o alimento pode estar com data de validade vencida, em bom estado de conservação ou estragado. Um de nossos interlocutores, ex-morador de rua, narrou como é se alimentar do lixo.

Comer do lixo, no começo é muito difícil, chorei a primeira vez que precisei fazer isso, lembrava da vida que tinha vivido e daquela condição que eu tava naquele momento. Mas depois virou um costume quase natural, rasgava sacolas de lixo que ficava dentro de caçambas próximo a rodoviária, também buscava os lixo de restaurante e lanchonete (Adjeferson).

Nos lixos de supermercados, peixarias, feiras livres, principalmente nos horários conhecidos como "xepa", o povo da rua busca alimentos. É oportuno ressaltar que a cidade produz um "lixo" que não se constitui só de alimentos. Reciclando o lixo as pessoas organizam nas ruas o espaço que vai lhes servir de morada, montam a "maloca", usando cadeira, mesa, pedaços de lonas, tecidos, utensílios domésticos velhos e gastos, sofás, dentre outros numerosos móveis e objetos encontrados nas ruas. Parafraseando Kasper (2006, p. 157), presta-se uma nova utilidade aos objetos, alterando sua forma e função, efetua-se uma verdadeira reinvenção dos objetos.

\section{Trabalhos QUe FAZEM NAS RUAS}

Conforme verificado em nossa pesquisa há muitos moradores de rua trabalhando na economia informal, sem terem um registro na Carteira de Trabalho e uma profissão formalmente reconhecida, são subempregados. Nessa condição encontramos ocupando as ruas os desempregados de longa duração, inclusive os que trabalharam na Administração Pública, bem como jovens que sequer tiveram a oportunidade do primeiro emprego. Encontramos também egressos do sistema prisional que após cumprimento de pena são liberados nas ruas, portando apenas a roupa do corpo e o alvará de soltura, tendo como responsabilidade individual conseguir emprego e moradia para não retornarem ao sistema penitenciário. Sem "eira nem beira" são encontrados com frequência vagando pelas ruas e/ ou sentados em bancos das praças da cidade de Vitória.

Os diversos arranjos para conseguir algum ganho podem se efetuar também por meio de outros expedientes. Ao conversar com a "Dama Limpinha", percebemos marcas em suas mãos e quando perguntada do que se tratava, respondeu: "Me queimei preparando angu na casa de uma mulher, às vezes trabalho e recebo $\mathrm{R} \$ 20,00$ pelo serviço." 
Não só os cidadãos domiciliados acolhem essa mão de obra pagando por pequenos serviços, o mesmo ocorre com o comércio. O dono de uma pastelaria oferece alguns trocados para que um popular de rua acondicione o bagaço da cana, organizando-o para a coleta de lixo. Os artesãos da feira de arte e alimentação fazem o mesmo para outros moradores de rua ajudarem a transportar, montar e desmontar suas barracas na Praça Costa Pereira e na Praça dos Namorados (região nobre da capital do estado).

Na rua é possível encontrar trabalho com agilidade, como lavar ou guardar carros particulares, uma prática muito comum entre aqueles que sobrevivem da rua. A construção civil costuma ser alternativa viável para quem tem habilidades na área, como ajudante de pedreiro, eletricista ou pintor de parede. Há momentos em que fazer "programa" pode ser uma saída para conseguir dinheiro rápido. As mulheres moradoras de rua usam desse expediente inclusive para sustentar o companheiro, se o mesmo consentir. Quando não há consentimento do companheiro, a tática é se ausentar por alguns dias e retornar após a realização desse expediente.

Mas é na catação de material reciclável onde se encontra o maior número de trabalhadores em situação de rua. Segundo relatório da Secretaria Municipal de Assistência Social (SEMAS), em média 100 catadores de materiais recicláveis circulam nas ruas de Vitória e são conhecidos como "carrinheiros". Usando carrinhos de madeira ou de latão com quadro rodas, seguem dia e noite na catação de papelão, alumínio, ferro, plástico, latinhas de bebidas, vidro e até mesmo lixo eletrônico que são vendidos aos "sucateiros" (depósitos de lixos) ou ferrosvelhos espalhados pelo município. No caso da cidade de Vitória, concordamos com D'ávila (2010, p. 61) ao escrever que: "As relações com os donos dos ferrosvelhos revestem-se de ambiguidade nas redes de convivência dos catadores". O pagamento que recebem pelo material vendido é irrisório, por vezes reduzido a um prato de comida ou uma garrafa de "meiota" (cachaça), fazendo às vezes do que poderia se chamar de pagamento pelo material vendido. Por outro lado, "[...] os ferros-velhos são uma das raras conexões, dentro da rede de sociabilidade, que vinculam os catadores que moram nas ruas a um ponto "fixo" da cidade" (D’ÁVILA, 2010, p. 61). Arriscamo-nos a dizer que no cerne dessa questão encontra-se uma relação trabalhista de semiescravidão.

Muito em função da longa distância no trajeto percorrido entre os locais em que exercem suas atividades até suas residências, preferem dormir nas ruas e retornar para a família somente nos finais de semana. A noite é tida com um bom momento para catação, horário em que a maioria da população coloca sacos de lixo nas calçadas ou caçambas à espera dos caminhões coletores dos serviços de limpeza urbana.

\section{TÁticas de SEguranÇa E DEFESA NAS RUAS}

Os artefatos de proteção nas ruas tanto podem ser um bastão de ferro ou de madeira, quanto uma faca simples ou mesmo um facão. Esses instrumentos irão servir para defesa de possíveis ameaças ou para espantar invasores indesejados na "maloca". "Chico doce" é o nome usado por determinado grupo de rua 
para se referir a um bastão confeccionado para defesa e "viana" o termo que utilizaram para se referir a um facão. $\mathrm{Na}$ verdade, esses nomes expressam as táticas elaboradas para que os instrumentos não sejam identificados de pronto.

A pesquisa realizada mostrou que quando se ocupa um território geográfico nas ruas é preciso garantir o "comando" e a "segurança" do lugar. Não são "permitidos" invasores que possam trazer "problemas", portanto, entendem que é necessário que alguém detenha o controle de quem deve "usufruir" do espaço. Também é necessário que essa "liderança" coloque "moral no pedaço" usando a força física se for o caso. Em nossas andanças não tivemos informações ou relatos sobre uso de arma de fogo. A polícia aborda a população de rua a todo instante e portar arma de fogo não seria nada estratégico em suas caminhadas.

Uma faca, a chamada "arma branca" pelo sistema de segurança, parece mais apropriada para os andarilhos da cidade, tendo aí mais de uma utilidade, já que tanto serve para o preparo de alimentos quanto para ser utilizada no caso de autodefesa. Afinal, dormir nas ruas é um grande desafio. Para conseguir dormir somente se estiver "chapado" e o uso de substâncias psicoativas ajuda nesse momento. Sob o efeito de alguma substância é possível dormir em qualquer lugar com ou sem barulho, caso contrário o sono é permeado de muita turbulência.

A pesquisa nos trouxe relatos de abordagens truculentas por parte dos agentes da Segurança Pública contra quem habita as ruas. As queixas sobre espancamentos são inúmeras, as incidências de violações de direitos são quase uma constante contra esses sujeitos. O povo da rua muitas vezes se cala e não denuncia por medo de represália na calada da noite. Acompanhamos casos de mulheres que não se deixaram intimidar e partiram para o enfrentamento na defesa de seus pertences ao verem os mesmos sendo incinerados. Carregam muitos objetos nas mochilas, são "bens" de valor afetivo, fotos de familiares, documentos pessoais, alvará de soltura, resultados de exames médicos, kit de higiene pessoal, algumas mudas de roupa, e outros "apetrechos" que à noite se transformam em leito para acomodar o corpo.

\section{REgRAS DE CONVIVÊNCIA NAS RUAS}

A convivência entre os grupos de rua não é feita por meio de regras fixas e escritas. Lima (1998, p. 81) apontou em estudo realizado nas ruas de Vitória, em 1998, que as regras nas ruas estão implícitas nas suas vivências e não são verbalizadas: "A maioria das regras envolvidas na produção e reprodução de práticas sociais são apenas tacitamente apreendidas pelos atores: eles sabem como "prosseguir". As regras nesses grupos, ainda segundo Lima (1998), não são aleatórias, mas, ao contrário, seguem uma regularidade e possuem uma lógica que diz respeito ao principio de manutenção de regras sociais. Durante o tempo em que realizamos a pesquisa de campo nem sempre ficava claro o que poderiam ser estas regras. 
A este respeito, Adjeferson Roseno (ex-morador de rua) nos contou que um homem em situação de rua ao assumir uma companheira grávida de outro, passa a assumir também seu filho, mesmo que os demais colegas "zombem" da situação. Os homens de rua costumam não se aborrecer com a "zombaria". Outro ponto de relevância e que parece funcionar também como uma regra nas ruas é "[...] não trocar alimentação por drogas: tipo se ganhou uma cesta básica, ela não pode virar moeda para compra de drogas", afirma Adjeferson, e a punição para esse ato é a expulsão do grupo. Um irmão de rua não pode roubar o outro. Para esse caso a punição é severa, o indivíduo pode apanhar do grupo ou da pessoa contra quem tenha feito o furto. Quando um morador de rua vai preso em hipótese alguma deve "alcaguetar" um companheiro, essa é uma regra importante entre eles. Uma regra também considerada das mais importantes é não roubar nas proximidades do espaço em que o grupo estiver ocupando, como também não guardar objetos adquiridos dessa forma.

"Cafanhate" na rua é "dar em cima" da mulher do outro, portanto tal ação é proibida e quem a pratica também poderá ser punido, tanto pelo grupo quanto pelo sujeito que se sentiu desrespeitado. A punição pode ser física. Quando esta regra é quebrada ninguém interfere para defender o sujeito que estiver apanhando, pois todos concordam que quem mexe com a mulher alheia está errado.

Já sabíamos de certa proteção com os profissionais que estabelecem vínculos com a população em situação de rua, mas o fato de tratar-se de uma regra foi uma surpresa. Quando se cria um vínculo com pessoas próximas ou um técnico é normal que todos na rua saibam tratar-se de alguém que não se pode roubar ou fazer agressões físicas. A primeira pessoa da galera da rua com quem essa pessoa fizer contato ficará responsável em avisar aos demais para que ela não seja molestada. As pessoas que trabalham com a população de rua devem ser protegidas pelos grupos de rua, afirmou Adjeferson. Saber acolher quem os acolhe, eis a regra. Salvo em caso gravíssimo de uma postura ou atitude que traga prejuízo ou constrangimento a um popular de rua, como por exemplo: uma agressão física ou uma delação à Polícia, bem como situações de abuso sexual, em que o abusador é alguém que deveria proteger. Nesse caso haverá consenso entre a população de rua e a pena também pode ser severa. Também é proibido roubar nos albergues, a punição também é física, sendo aplicada por aqueles que se utilizam daqueles serviços.

Os gestos de solidariedade fazem composição com as regras tecidas na vida nas ruas, pois também acontece entre os irmãos de rua compartilharem alimentos com um camarada ou efetuarem trocas de informações que possam trazer benefícios comuns. Observamos entre moradores de rua a socialização no uso do vestuário que ganham. O mesmo ocorre quanto ao uso de substâncias psicoativas, principalmente a cachaça que é muito compartilhada nas rodas de conversa. 


\section{O HABITAR AS RUAS}

No lugar de habitar uma casa, os moradores de rua fazem da cidade sua moradia, conforme analisa Fonseca (2003) ao discutir a cidade como espaço de produção de territórios existenciais. Como aponta Gomes (2006, p. 71): “[...] a não-fixação domiciliar, que caracteriza o modo de vida da maior parte da população que habita a rua, promove uma intensa mobilidade espacial e, portanto, existencial, que faz deste segmento um dos representantes nômades da cidade."

A rua é "residência fixa" por um longo período de tempo para algumas pessoas, como foi verificado no mapeamento realizado. Podem permanecer semanas, meses ou anos no mesmo local (bairro e logradouro público), tudo depende da tolerância dos cidadãos domiciliados no entorno. Em muitas situações, são as circunstâncias que os tornam itinerantes, fato também que por sua vez demandou mais tempo no processo de nossa pesquisa, pois a cada momento tornava-se necessário iniciar uma busca ativa pelas pessoas convidadas para conversarmos acerca da vida nas ruas da cidade. A rotina de migração pela cidade é outro processo que não difere com relação aos diversos grupos que vivem nas ruas, seja na cidade de Vitória ou em qualquer grande metrópole. Pressão e repressão estão presentes, não se diferenciando nos modos de ação. As ameaças, seguidas de práticas violentas, podem partir tanto dos agentes dos serviços públicos, como de moradores domiciliados, expressando a intolerância da sociedade com relação à população em situação de rua.

Existem outros fatores que forçam a migração no interior da cidade, entre os municípios e os diversos estados da federação. Neste processo, como já apontado, em algumas cidades do Espírito Santo, os espaços de albergamento são inexistentes ou os leitos nos albergues não são suficientes, provocando um fluxo contínuo de pessoas em situação de rua para a capital do Estado. As medidas utilizadas para lidar com esta demanda têm sido marcadas por atitudes contraditórias: as autoridades municipais e estaduais se posicionam muitas vezes sendo coniventes com as práticas de repressão contra a população em situação de rua. A cada repressão os habitantes das ruas, quando possível, levantam acampamentos, e montam "casa" em outros pontos da cidade. Na itinerância forçada, o novo "habitat" pode ser um espaço já habitado por outros moradores de rua, desde que haja permissão do "comando do lugar", mas também podem começar uma "nova maloca" que possibilite tecer no entorno uma rede de sobrevivência. Talvez seja por essa razão que as ocupações não ocorram em bairros periféricos da cidade. Gomes (2006, p. 80) faz uma bela ilustração assemelhando esse público com os animais que carregam a casa nas costas: "Gente Caracol traz uma casa carregada junto ao corpo, [...] A ideia de casa aqui proposta contrapõe ao modelo familiar burguês: ambiente sem nenhum grau de porosidade, que não se deixa penetrar pelo cheiro, pela sujeira, pelo ruído das ruas."

Não juntar muitos objetos é uma tática para a mobilidade nas ruas. Sacolas e mochilas são utilizadas para transportar objetos pessoais. Delas podemos vê-los retirar alguns objetos: mudas de roupas, documentos, sabonetes, xampu, pentes, 
cremes, escovas e pasta de dentes quando os têm, “[...] nós que ficamos na rua não podemos carregar muita coisa, é só uma bolsa com alguma coisa dentro. Se a gente precisar sair do lugar fica mais fácil pra carregar", argumentou.

\section{FAMÍlias MORANDO NAS RUAS: QUANDO OS SISTEMAS DE DIREITOS ENCARCERAM A VIDA}

A maioria dos moradores de rua é formada por homens sós, no entanto, pudemos perceber ao final de nossa pesquisa um grupo significativo de mulheres vivendo nas ruas, muitas delas jovens. Este grupo aponta para uma nova demanda, a saber: as mulheres grávidas em situação de rua. Na cidade de Vitória não existe albergamento para mulheres com filhos e/ou famílias, como também não há na cidade serviços de atenção a famílias ou mulheres grávidas em situação de rua.

Foi possível verificar que famílias estão se constituindo nas ruas e, ao mesmo tempo, impedidas de conviverem. Os albergamentos atendem a grupos específicos ou são exclusivos para pessoas adultas, ou para crianças e adolescentes. Uma vez em situação de rua, os membros desta família (pai, mãe e filhos) são separados em instituições distintas, fato este que pode culminar muitas vezes em graves rompimentos de vínculos.

Um casal que participou da pesquisa se conheceu aos 16 anos, em Minas Gerais, e estão juntos há 20 anos, hoje já são avós. Em função de diversas dificuldades, como o desemprego, a perda da moradia e o uso de drogas, num dado momento foram viver na rua com os seis filhos. Por um período de tempo, todo o grupo familiar foi assistido pela rede de proteção básica da assistência social. Mas as ações efetuadas não foram suficientes para lidar com as demandas desse núcleo familiar. Os filhos foram separados em espaços de abrigamento distintos, divididos por faixa etária, e o casal permaneceu nas ruas por um longo período até serem acolhidos pelas equipes de abordagem de rua. Ao final, perderam três filhos definitivamente, posto que as crianças foram encaminhadas para a adoção internacional.

Uma vez estabelecido o processo de abrigamento para a criança e o adolescente, inicia-se a contagem de um prazo previsto por lei para que os mesmos não sejam institucionalizados. O sistema de garantias de direitos (Conselhos Tutelares e Juizado da Infância e da Juventude), respaldado no Estatuto da Criança e do Adolescente, prevê uma família substituta para as crianças que estejam abrigadas por até dois anos. O tempo da lei não corre no mesmo ritmo e percurso para quem está em situação de rua. Hebert e Lilian, os pais destas crianças, precisaram de mais que dois anos para ficarem sem uso de drogas, reorganizar uma casa e conseguir um emprego para terem seus filhos de volta. Estas foram as condicionalidades (im)postas para terem de volta a guarda dos filhos. E foi no final desse prazo de dois anos que receberam a notícia de que os três filhos menores tinham sido entregues para adoção internacional. Ambos recorreram, solicitaram intervenção da Defensoria Pública, por meio do Conselho de Direitos do Município de Vitória. Contudo, a adoção no Brasil, uma 
vez efetivada, torna-se de caráter irreversível. Sob a aura da proteção integral da criança e do adolescente há outras mulheres em situação de rua que têm perdido a guarda de seus filhos ainda na maternidade, logo após o parto.

\section{OS VÍNCULOS FAMILIARES PARA QUEM CAI NA "PISTA"}

Podemos falar em vínculos rompidos e/ou fragilizados, da mesma forma como têm sido abordado nas diversas pesquisas que referenciaram nossos estudos. Mas estar em situação de rua não significa necessariamente que houve rompimento definitivo de vínculos familiares.

Conversamos com pessoas que passaram toda adolescência em situação de rua, cujas relações familiares estavam extremamente fragilizadas e que, muitos anos depois, retomaram os vínculos familiares, estreitandoos principalmente por meio de visitas que passaram a fazer à família e à comunidade em que viviam. Ainda assim são poucos os casos dos que rompem com a rua para fazer o caminho de volta para casa.

\section{CUIDADO COM O CORPO: O BANHO, A LIMPEZA DAS ROUPAS E VASILHAS}

Ao contrário do que se pensa, o povo da rua se preocupa com cuidados pessoais, principalmente com o banho diário. Mantém nas ruas hábitos de higienização convencionalmente adquiridos. Mas essa não é uma regra seguida por todos. Tanto homens como mulheres buscam pontos na cidade que possam ofertar higienização e, como são poucas as alternativas, muitas vezes torneiras em postos de gasolina, chafariz ou quiosques são utilizados não só para banhos, mas também para lavagem de vasilhas e roupas. O certo "[...] é que ficar sem banho incomoda", comentam. A coordenação da Hospedagem Noturna diz que mesmo não havendo leitos disponíveis para pernoite, muitas vezes a entrada de usuários é liberada para fazer alimentação e higienização.

Muitas vezes a própria comunidade colabora com quem deseja tomar um banho. Pastores das igrejas evangélicas são frequentemente referidos pela população de rua por disponibilizarem suas casas ou os espaços da igreja para acolher com um banho ou alimentação. Patrícia afirma não conseguir ficar sem fazer higienização do corpo, faz uso de espaços públicos para garantir esses cuidados: "[...] ali embaixo, não sei o nome só sei que é Igreja, o padre dá almoço, dá café. Eu sei que entro lá dentro, quando tá fechado pulo o muro e tomo meu banho rapidinho, me enxugo."

Diferentemente do que veicula-se de forma naturalizada em nossa vida cotidiana, os habitantes das ruas gostam de se arrumar para participar de reuniões, para ir às festas, passeios culturais, ou mesmo visitar um familiar. Fazer a barba, pentear os cabelos e/ou vestir uma roupa limpa compõem também os rituais do seu dia a dia. 


\section{Festas e outros batuques}

Os modos de se divertir também são inventados nas ruas, principalmente à noite quando os membros do grupo se reúnem e "rolam" muitas brincadeiras entre eles, fazem chacota um do outro, mencionando situações hilárias que vivenciaram no decorrer do dia. Amigos costumam aparecer para visitas e compartilham da cachaça. Elisa considera que na rua as amizades são sinceras, sente falta dos companheiros quando retorna para a casa de sua família; "Na rua fazíamos o bonde da praia", fala Elisa.

[...] O "Bonde da Praia" era todo mundo da maloca, ir todo morador junto pra praia de Camburi. A gente ia lá e fazia churrasquinho, levava umas latas e fazia comida [...] nossa, era a minha maior alegria, era o dia mais especial nosso. [...] (Elisa).

O que percebemos ao ficarmos atentas às táticas e astúcias forjadas nas ruas é que muitos objetos são recriados, melhor dizendo, são inventados de forma que passam a ter uma utilidade diferente daquela que comumente conhecemos. Processos de reciclagem entram em cena, transformando objetos descartados e degradados, reaproveitando-os de maneira muitas vezes inusitada. Reciclar, transformar, reaproveitar, inventar são práticas que tomam parte na garantia da sobrevivência nas ruas, o mesmo ocorrendo com o uso dos espaços da cidade, que podem ganhar outra funcionalidade. Quando esses moradores se instalam nas ruas, aí fabricam modos de existência que por vezes se diferenciam dos modos instituídos e, por vezes, também os repetem. Modos de vida que desafiam os nossos olhares naturalizados e o funcionamento das políticas públicas.

No lugar de acentuar os lugares conhecidos da população em situação de rua, ora como vítimas, ora como sujeitos vistos como perigosos, o que a pesquisa nos mostrou foi uma imensa riqueza e complexidade. A pesquisa efetuada nos fez mergulhar nestas criações cotidianas, contribuindo para problematizar certo modo de pensar que coloca os moradores de rua na condição de pobres "miseráveis" urbanos, incapazes e sem inventividade.

As narrativas acerca da vida nas ruas nos mostraram um cotidiano inusitado, que abarcou as maneiras como se organizam para sobreviver e habitar as ruas; como driblam o sistema de segurança que, ao contrário de protegê-los, muitas vezes age com ações truculentas sobre os mesmos; como funcionam os serviços públicos de limpeza urbana das ruas que insistem em tratá-los como entulho, ao despejar nos locais em que dormem jatos de água com carro-pipa, utilizandose também de caminhão basculante e varredeiras para recolher seus pertences pessoais. Para alguns cidadãos domiciliados trata-se da "limpeza social", pois junto com o entulho parte da sociedade deseja que as pessoas sejam "recolhidas".

De maneiras diversas o povo da rua se vale de táticas de sobrevivência, e estas se expressam nos locais que escolhem para dormir; no modo como se dão as relações com o mundo das drogas, com a população domiciliada, com a polícia e os comerciantes; em suas redes de camaradagem; nas regras e alianças 
partilhadas; na culinária inventada e preparada nas panelas improvisadas de lata reciclada e no fogareiro produzido artesanalmente; nas manipulações e na correria que não se restringem somente ao ato de manguear; nos amores construídos; nas perdas que deixaram marcas, nas lágrimas contidas e nos risos expressos nas narrações da própria vida.

\section{Notas}

${ }^{1}$ O Disque-Vitória 156 é um serviço municipal de atendimento ao público através do telefone 156, em que os comerciantes, as pessoas domiciliadas e os turistas podem registrar suas demandas, requisitar diversos serviços públicos, denúncias e insatisfações com a cidade.

${ }^{2}$ Centro de Referência Especializado da Assistência Social para a População de Rua

${ }^{3} \mathrm{O}$ morador de rua define "manguear" como o ato de entrar na mente das pessoas. Conta-se uma história ou situação que possa sensibilizar e, assim, convencer o outro a fazer uma doação, normalmente as solicitações são em dinheiro.

${ }^{4}$ Kasper (2006) utiliza o termo cidadão domiciliado para designar o indivíduo que mora em uma habitação permanente, a casa residência.

${ }^{5}$ O Artigo 155 compreende "Subtrair, para si ou para outrem, coisa alheia móvel". 


\section{REFERÊNCIAS}

ALVAREZ, J.; PASSOS, E. Cartografar é habitar um território existencial. In: PASSOS, E.; KASTRUP, V.; ESCÓSSIA, L. (Org.). Pistas do método da cartografia: pesquisa-intervenção e produção de subjetividade. Porto Alegre: Sulina, 2009. p. 131-149.

BAPTISTA, L. A. A cidade dos sábios: reflexões sobre a dinâmica social nas grandes cidades. São Paulo: Summus, 1999.

BRASIL. Ministério do Desenvolvimento Social e Combate a Fome. Politica Nacional de Assistência Social - PNAS/2004. Brasília: MDS, 2005.

BRASIL. Ministério do Desenvolvimento Social e Combate à Fome. Rua: aprendendo a contar - pesquisa nacional sobre a população em situação de rua. Brasília: Secretaria de Avaliação e Gestão da Informação, 2009a. Disponível em: $\quad<$ http://www.mds.gov.br/gestaodainformacao/disseminacao/avaliacaoe-monitoramento/2009/rua-aprendendo-a-contar-pesquisa-nacional-sobre-apopulacao-em-situacao-de-rua/arquivos/rua.pdf/download>. Acesso em: 30 jun. 2011.

BRASIL. Política nacional de inclusão social da população em situação de rua. 2009b. Disponível em: <http://www.recife.pe.gov.br/noticias/arquivos/2297. pdf $>$. Acesso em: 30 jul. 2011.

CASTEL, R. As metamorfoses da questão social: uma crônica do salário Petrópolis, RJ: Vozes, 1998.

CERQUEIRA. M. B. Pobres, resistência e criação: personagens no encontro da arte com a vida. São Paulo: Cortez, 2010.

CERTEAU, M. de. A invenção do cotidiano: artes de fazer. Petrópolis, RJ: Vozes, 2008. v. 1.

CERTEAU, M. de. A invenção do cotidiano: morar, cozinhar. Petrópolis, RJ: Vozes, 2011. v. 2.

D’ÁVILA, R. Vidas insurgentes na cidade-casa. 2010. Dissertação (Mestrado em Psicologia Institucional)-Programa de Pós-Graduação em Psicologia Institucional, Universidade Federal do Espírito Santo, Vitória, 2010.

DELEUZE, G; GUATTARI, F. Mil platôs: capitalismo e esquizofrenia. Rio de Janeiro: Editora 34, 1995. v. 1. 
FONSECA, T. M. G. A cidade subjetiva. In: FONSECA, T. M. G.; KIRST, P. G. (Org.). Cartografias e devires. Porto Alegre: UFRGS, 2003. p. 62-68.

FUGANTI, L. A formação do pensamento ocidental: aula 1 de 29/3/2001. Disponível em: <http://escolanomade.org/pensadores-textos-e-videos/fugantiluiz/a-formacao-do-pensamento-ocidental-aula-1>. Acesso em: 23 maio 2011.

GOMES, R. C. M. Gente caracol: a cidade contemporânea e o habitar as ruas. 2006. Dissertação (Mestrado em Psicologia Social e Institucional)-Programa de Pós-Graduação em Psicologia Social e Institucional, Universidade Federal de Porto Alegre, Porto Alegre, 2006.

GUATTARI, F.; ROLNIK, S. Micropoliticas: cartografias do desejo. Petrópolis, RJ: Vozes, 1986.

KASPER, C. P. Habitar a rua. 2006. Tese (Doutorado em Ciências Sociais)Instituto de Filosofia e Ciências Humanas, Universidade Estadual de Campinas, São Paulo, 2006.

LIMA, M. H. T. de. Cidade de papelão: mocós, cachangas e malocas. Vitória, ES: EDUFES, 1998.

MENDES, M. V. B. Um estudo sobre os territórios existenciais da população de rua de Belo Horizonte. 2007. Dissertação (Mestrado em Sociologia)-Programa de Pós-Graduação em Sociologia, Universidade Federal de Minas Gerais, Belo Horizonte, 2007.

PASSOS, E.; BARROS, R. B. A. Cartografia como método de pesquisaIntervenção. In: PASSOS, E.; KASTRUP, V.; ESCÓSSIA, L. (Org.). Pistas do método da cartografia: pesquisa-intervenção e produção de subjetividade. Porto Alegre: Sulina, 2009. p. 17-31.

SANTOS, M. Por uma outra globalização: do pensamento único à consciência universal. São Paulo: Record, 2000.

SILVA, M. L. L. da. Trabalho e população em situação de rua no Brasil. São Paulo: Cortez, 2009.

Recebido em: 17 de agosto de 2013

Aceito em: 23 de julho de 2014 